\title{
Earthquake damage on the vaulted nave of the Atlatlahucan Ex-Convent church in Morelos, Mexico
}

\author{
Guillermo Martinez ${ }^{1}$, Jose M. Jara ${ }^{2}$, Bertha A. Olmos ${ }^{3}$ \\ School of Civil Engineering, Universidad Michoacana de San Nicolás de Hidalgo, Morelia, Mexico \\ ${ }^{1}$ Corresponding author \\ E-mail: ${ }^{1}$ guillermo.mtzruiz@gmail.com, ${ }^{2}$ jmjara70@gmail.com, ${ }^{3}$ ba.olmos@gmail.com
}

Received 19 July 2019; accepted 4 August 2019

DOI https://doi.org/10.21595/vp.2019.20914

Check for updates

Copyright $(0) 2019$ Guillermo Martinez, et al. This is an open access article distributed under the Creative Commons Attribution License, which permits unrestricted use, distribution, and reproduction in any medium, provided the original work is properly cited.

\begin{abstract}
The State of Morelos, in Mexico, has an architectural heritage conformed by 4614 religious and civil buildings, many of which were severely affected by the earthquake that occurred on September 19, 2017, which also caused damages to the built heritage in the states of Puebla, Tlaxcala, Mexico and Mexico City. A total of about 2800 heritage buildings suffered different damages degrees, reaching in many cases the collapse of elements such as vaults, domes, bell towers as well as their cloisters. The Ex-Convent of San Mateo in Atlatlahucan, Morelos, suffered damages on its main nave, in the pinnacles on the longitudinal side walls as well as in the clock box located on the front façade. In the present work, an analysis is made of the damages observed in the building, as well as a preliminary analytical diagnosis of the behavior of the main nave in order to propose future reinforcement actions for the building.
\end{abstract}

Keywords: earthquake, dynamic properties, historical buildings, damages.

\section{Introduction}

The Ex-Convent of San Mateo, Atlatlahucan, was begun in 1535 and completed in 1567 and is part of the eleven convents that integrate the well-known route of the convents. This building was recognized in 1994 by UNESCO as cultural heritage of the humanity (Fig. 1). On September 19, 2017 at 13:14:40 local time, a 7.1 magnitude earthquake occurred with an epicenter of coordinates 18.4 North latitude and -98.72 West longitude and a hypocentral depth of $57 \mathrm{~km}$, according to data from the Institute of Geophysics of the Autonomous National University of Mexico, UNAM, (Fig. 2). The earthquake had a seismogenic mechanism of "normal or traction" faulting produced by the Cocos plate subducted below the North American plate, as shown in the focal mechanism of Fig. 2. The mentioned fault consists in the rupture by traction of the subducted plate at intermediate depths $(50-60 \mathrm{Km})$, occurring in most cases within the earth's crust (which is why they are also known as "intraplate" earthquakes) and at short distances from urban centres.

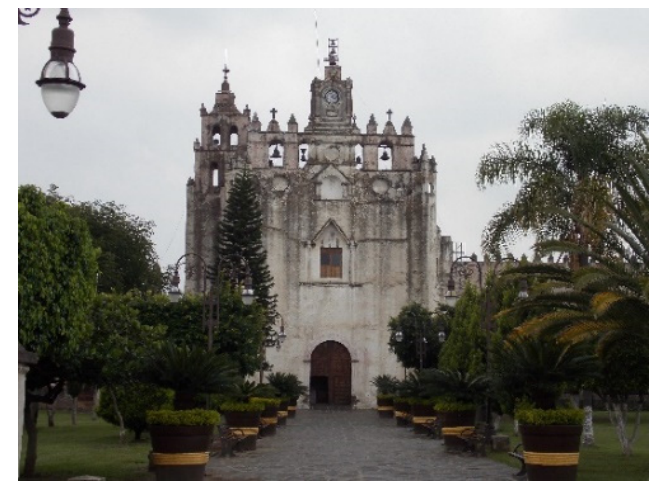

a)

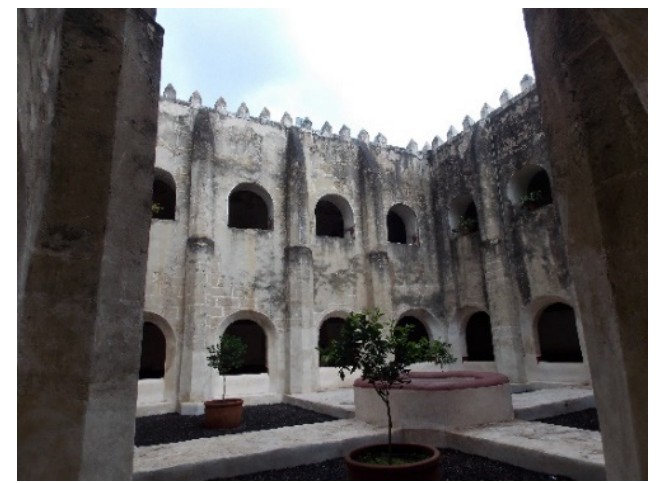

b)

Fig. 1. a) Main façade and b) cloister of the Atlatlahucan Ex-Convent before September 19, 2017, earthquake 


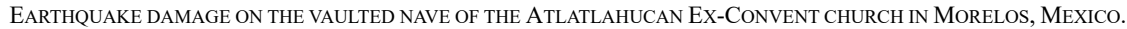
Guillermo Martinez, Jose M. JARA, BERTha A. Olmos
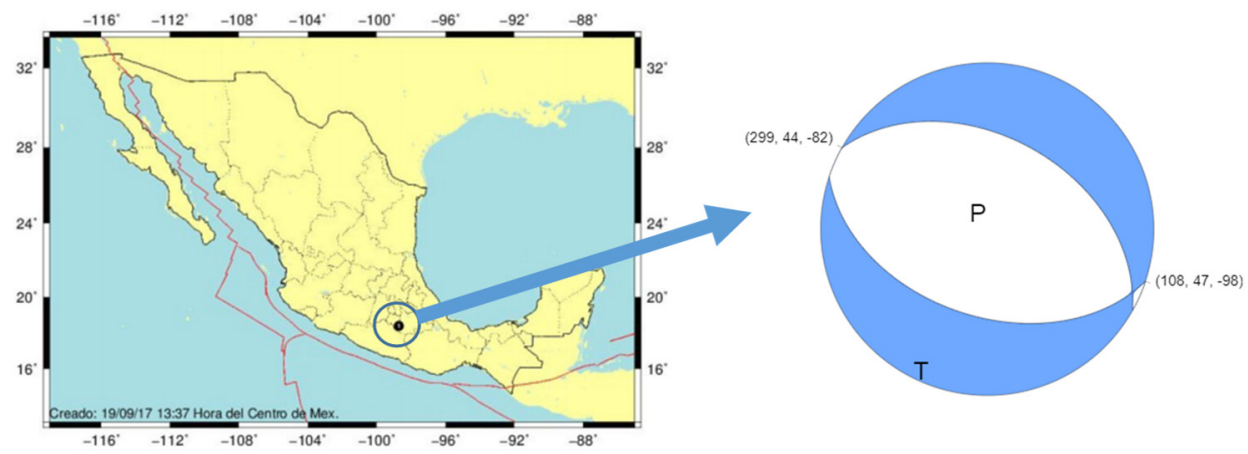

Fig. 2. a) Epicenter location and b) focal mechanism obtained by the USGS of the September 19, 2017, earthquake

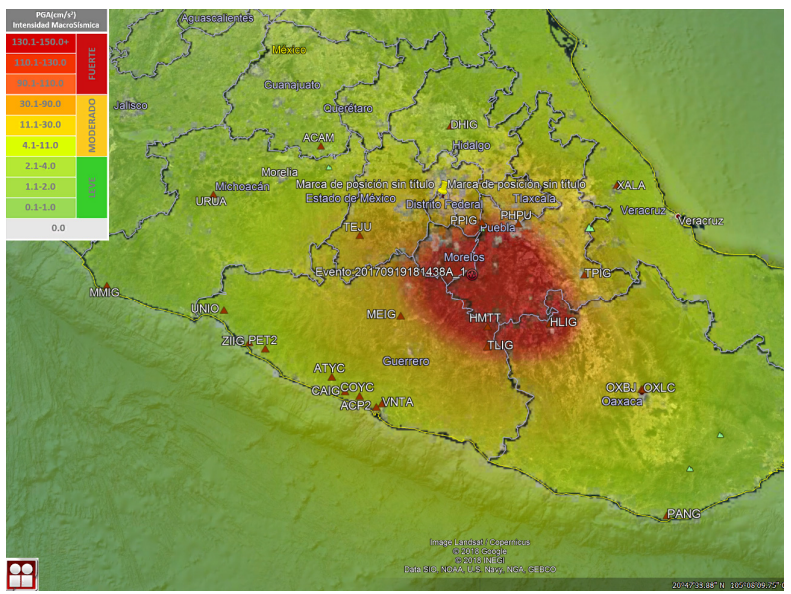

a)

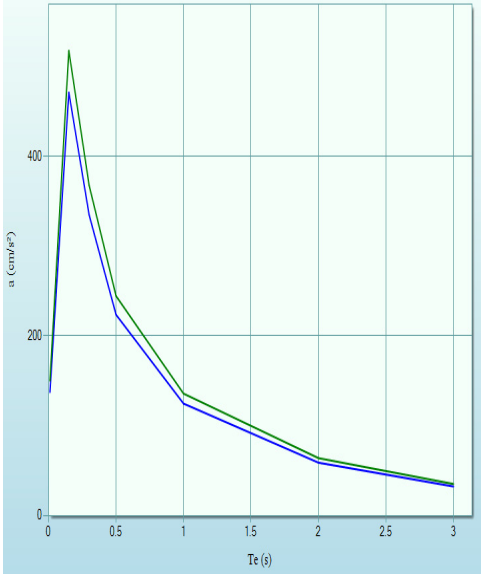

b)

Fig. 3. a) Intensities map performed by the Engineering Institute of the UNAM and b) uniform seismic hazard spectrum on stiff soil

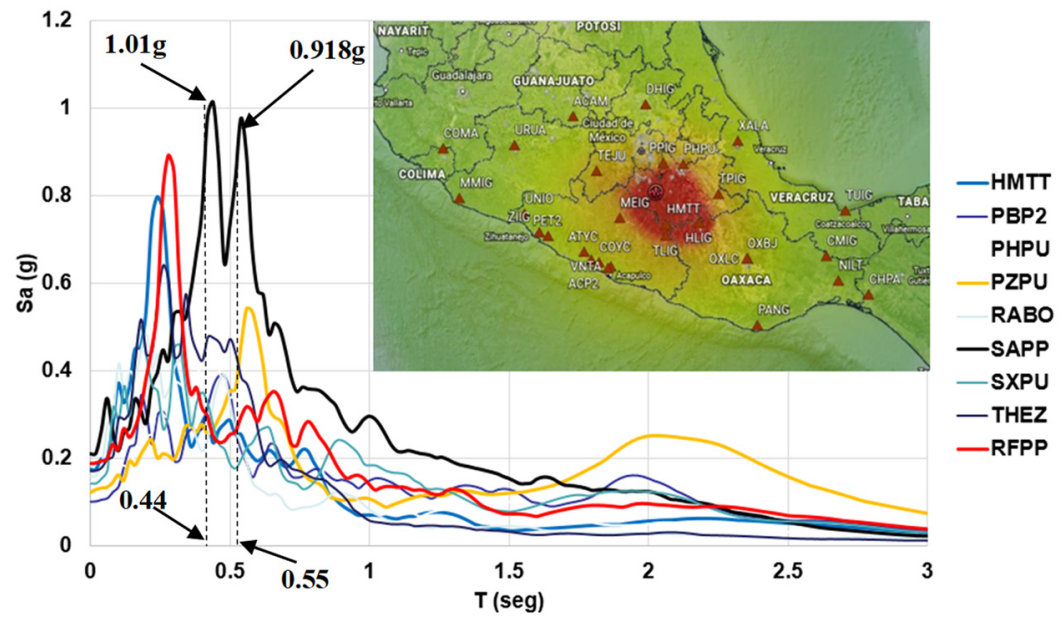

Fig. 4. Response spectra of the nine seismic stations nearest to the building

\section{Earthquake characteristics}

Intensities map performed by the Engineering Institute of the UNAM, shows peak ground 
accelerations of 130.1 to $150 \mathrm{~cm} / \mathrm{s}^{2}$, maximum value that according to the site seismic hazard corresponds to the return period of 457.2 years (Fig. 3(a)), value that can be observed on the $\mathrm{Te}$ (s) equal to cero ordinate in the uniform seismic hazard spectrum (Fig. 3(b)), calculated on stiff soil [1].

Fig. 4 shows the response spectra of the seismic stations located near to the Ex convent, where it can be seen that the highest spectral amplifications of the acceleration occurred in a range of periods of vibration from 0.18 to 0.54 seconds, reaching a maximum value of $1.01 \mathrm{~g}$ associated to a 0.44 s vibration period.

\section{Observed damages}

Prior to the September 19, 2017 earthquake the barrel vault of the temple had a longitudinal crack in the intrados of the arch key, which seems to be recently been consolidated at the date of the picture (Fig. 5). After the seismic event, the probable consolidation with a high strength material produced the appearance of a system of two additional longitudinal cracks both sides of the original crack (Fig. 6), which evidences the fact that the application of materials with higher strength than the original can lead the appearance of additional damages that can generate unstable rigid blocks.

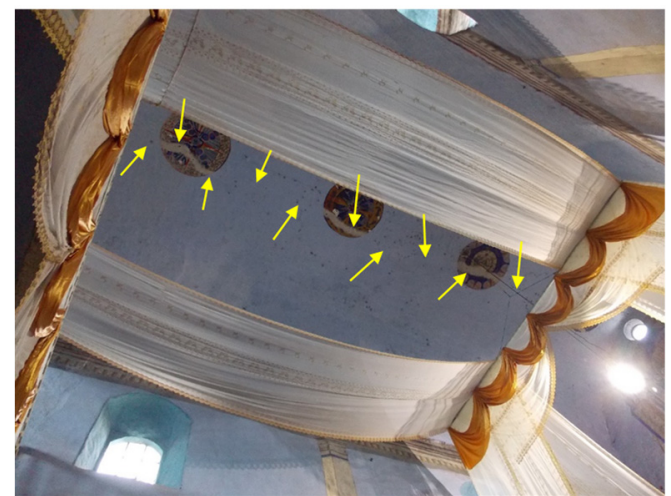

Fig. 5. Existing longitudinal crack recently consolidated (picture taken on September 21, 2016)

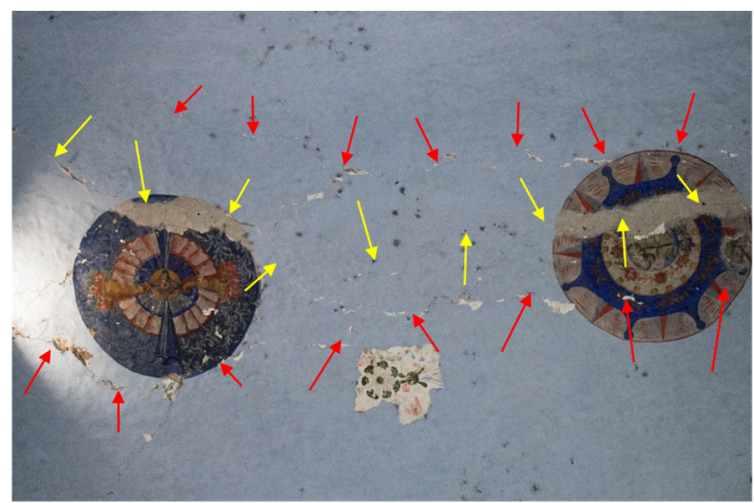

Fig. 6. Longitudinal cracks on the intrados of the main vault. The original crack (yellow arrows) and the new ones following the previous one at both sides (red arrows) are shown

\section{Seismic behavior of the barrel vault}

In order to understand the damages caused by the September 19, 2017 earthquake, two types of study were carried out, on the one hand, ambient vibration measurements were made on the 
floor of the cloister (Fig. 7) with the purpose of obtain the fundamental vibration period for the site, and on the other hand in an approximate way, a structural analysis of the main nave macroelement was performed using elastic finite elements and considering the highest pseudo-acceleration record, that is, the one corresponding to the SAPP seismic station (Fig. 4).

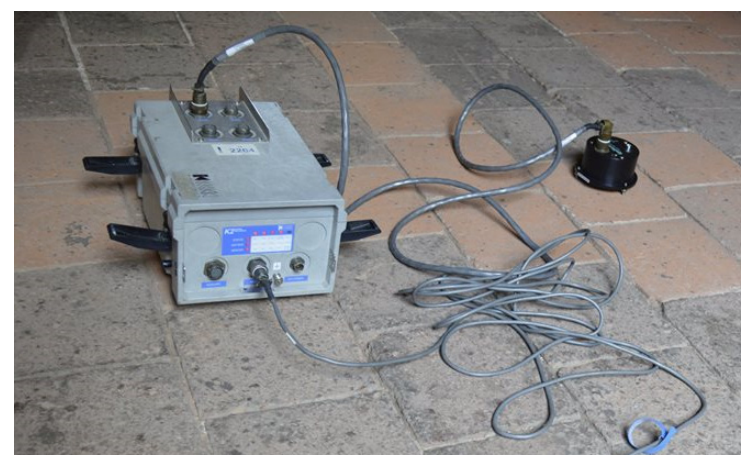

Fig. 7. Ambient vibration measurements on the cloister ground level

For the ambient vibration measurements performed on the cloister ground level a 24 bits K2 acquisition console and a triaxial ES-T sensor (Fig. 7) were used, both from the Kinemetrics brand. Two 10-minute acceleration measurements were taken at 200 samples per second, which were processed in the frequency domain to subsequently apply the H/V ratio technique [2]. With the above, a frequency of $1.81 \mathrm{~Hz}$ was obtained (Fig. 8) which is equivalent to a vibration period of 0.55 seconds, a value which is within the spectral range of maximum pseudoacceleration amplitudes (Fig. 4).

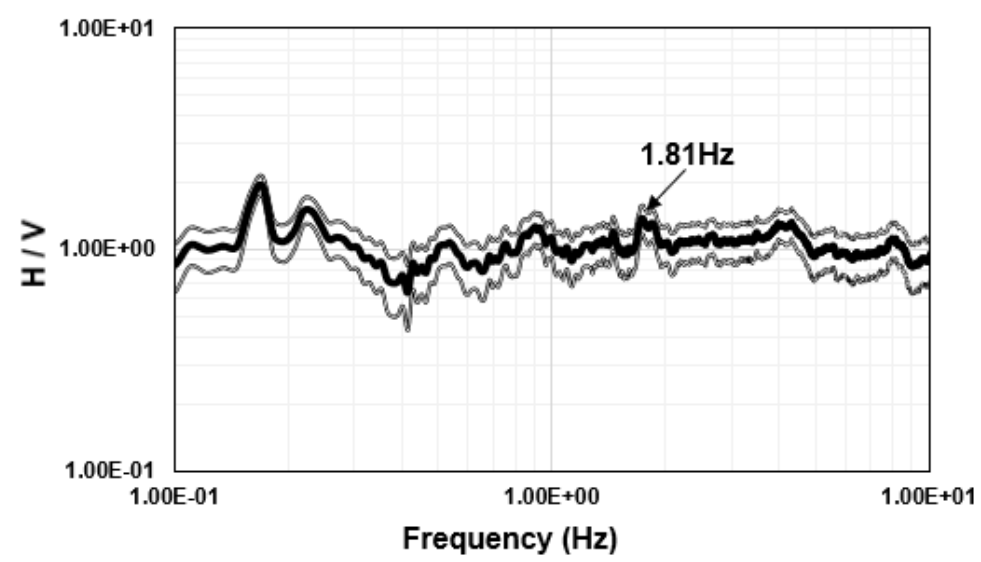

Fig. 8. H/V relationship on the cloister ground level

The hipocentral distances to the SAPP station and the Atlatlahucan Ex Convent were $107 \mathrm{~km}$ and $85 \mathrm{~km}$ respectively, so the spectral pseudoacceleration for the site 0.55 seconds ground period was at least of $918 \mathrm{~cm} / \mathrm{s}^{2}$ (Fig. 4). The two-dimensional finite element model was built using the geometric characteristics (Fig. 9) published by other authors [3], and was calibrated iterating the Young's Module until the fundamental period of the nave numerical model was equal to the obtained with the following formula [4]:

$T=0.0071 H+0.2197$,

where $H$ is the total height of the nave and $T$ it's the associated fundamental vibration period, equal to 0.34 seconds for this case. 
The structural analysis of the nave considering only its selfweight shows that in the intrados of the key, from its origin, tension stresses were already present with a value of $0.408 \mathrm{MPa}$ (Fig. 10(b)), which partly explains the observed crack in Fig. 5, and which had been previously repaired. This traction stress was produced by the horizontal thrust forces an whose effect can be seen in the deformed shape that was amplified for visualization purposes (Fig. 10(a)). It is shown that the maximum lateral displacement produced by the thrust was of almost half a millimeter $(0.04 \mathrm{~cm})$, enough to produce cracking due to the practically zero traction resistance of the ancient masonry.

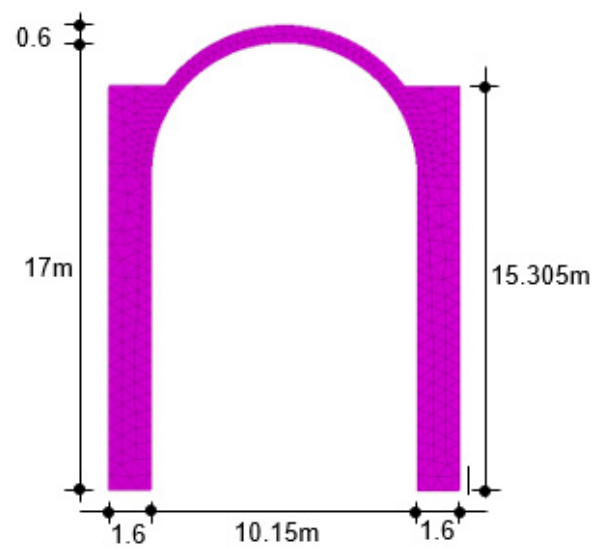

Fig. 9. FE mesh and transversal macroelement geometry for the Atlatlahucan nave

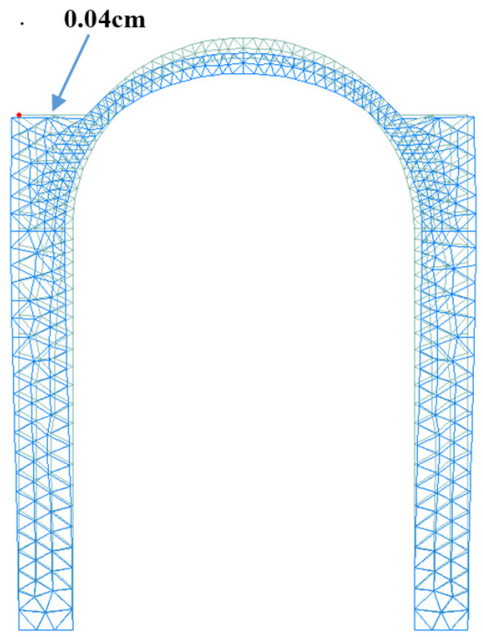

a)

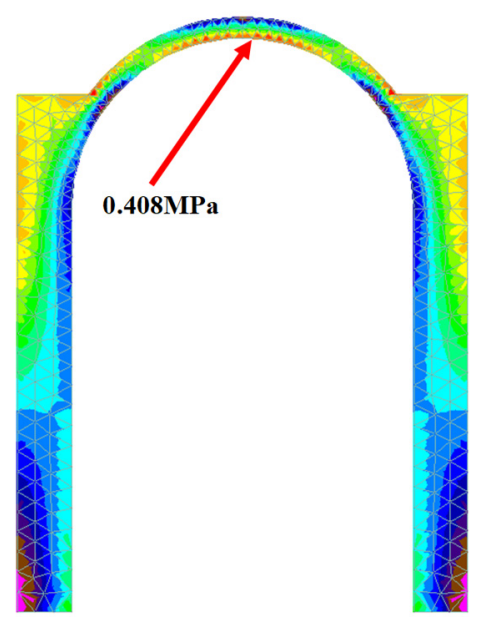

b)

Fig. 10. Elastic displacements and principal stresses for the selfweight load condition

The selfweight condition combined with the seismic forces produces the deformed configuration indicated in the left Fig. 11, in which it can be seen that the point located on the intrados of the nave suffered a lateral elastic displacement of $1.934 \mathrm{~cm}$, and in the zone of the kidneys by the extrados of the vault the lateral displacements reached $1.988 \mathrm{~cm}$. The deformed was again amplified for an ease visualization. The earthquake in fractions of a second changes direction, so the deformed image is reversed and consequently the associated damage. According to the in situ observed cracks, these displacements generated damages to the vault that could be classified as extensive for a relative value equal to 0.0011 .

The elastic principal stresses on the extrados of the kidneys of the vault reached 2.1 MPa while 
on its intrados reached $2.46 \mathrm{MPa}$ (Fig. 11(b)), values which significantly exceed the almost zero traction resistance for the ancient the masonry. The fundamental vibration period obtained after the calibration process was 0.343 seconds, which practically matches with that provided by the formula [4], and the first four vibration modes obtained are shown in the Fig. 12. Calculated modal participation factors were $66.492 \%, 0 \%, 16.227$ and $0 \%$ for each mode, so it can be notice that de damage zones match with de maximum vault modal amplitudes for the first and third modes.

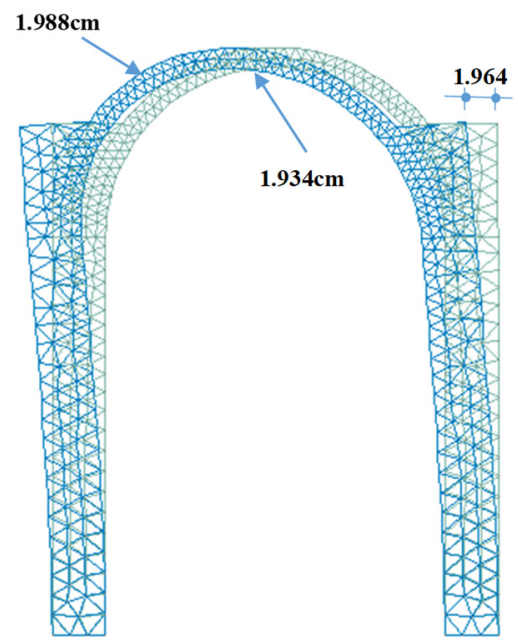

a)

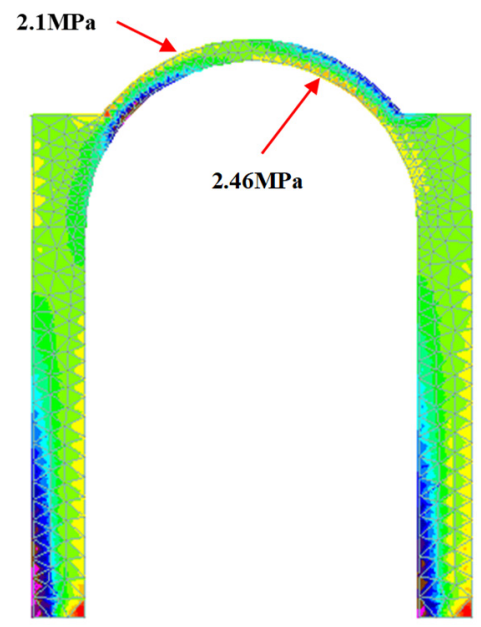

b)

Fig. 11. Elastic displacements and principal stresses for the selfweight + earthquake load combination

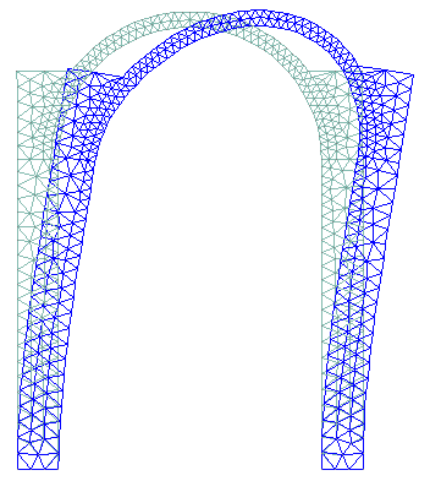

a) Mode $1(0.343 \mathrm{Seg})$

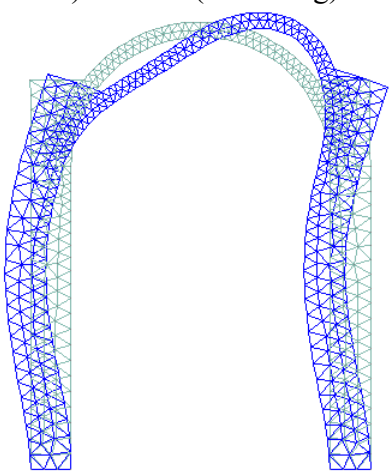

c) Mode 3 (0.061 Seg)

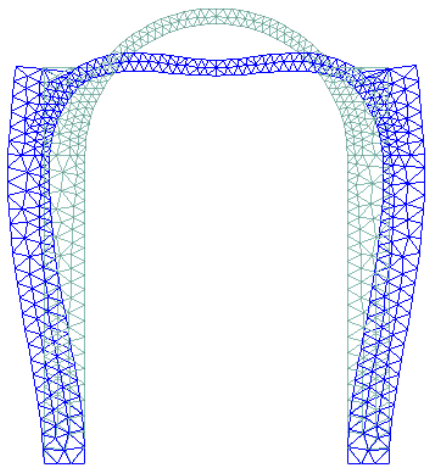

b) Mode $2(0.109 \mathrm{Seg})$

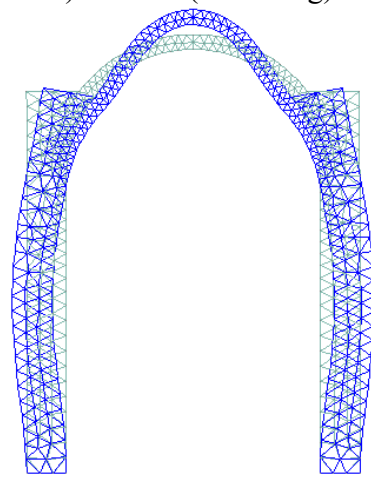

d) Mode 4 (0.046 Seg)

Fig. 12. First four vibration modes 
Fig. 13 shows the displacements and accelerations for the center point on the intrados of the key and it is observed that in the second 35.2 the maximum horizontal displacement of $1.934 \mathrm{~cm}$ mentioned above was reached, while the maximum acceleration occurs in the second 31.5 reaching a value of $640 \mathrm{~cm} / \mathrm{s}^{2}$.
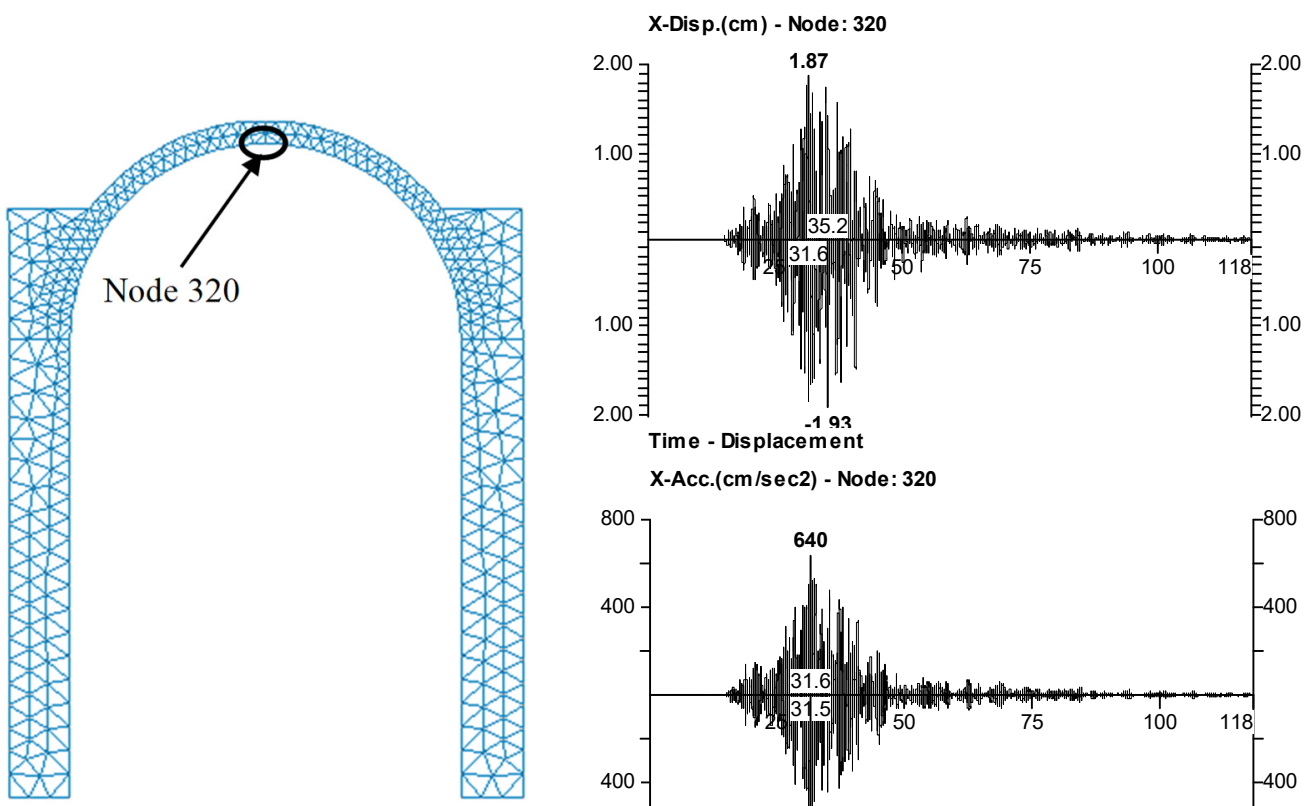

Time - Displacement

X-Acc.(cm/sec2) - Node: 320

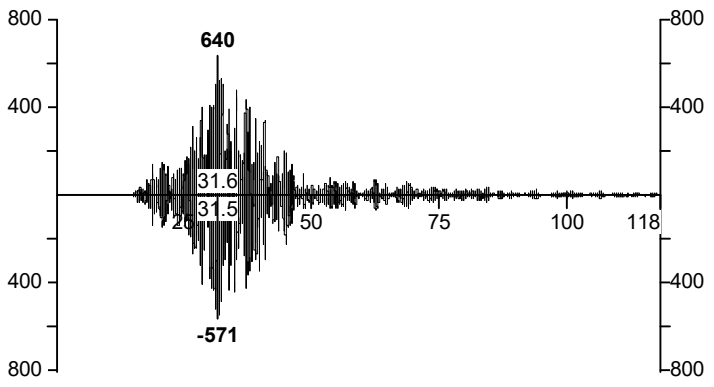

Fig. 13. Displacements and accelerations at node 320 of the nave

\section{Conclusions}

The Ex convent of San Mateo Apóstol in Atlatlahucan, in the State of Morelos, suffered extensive damage to its main nave with the earthquake of September 19, 2017. Such damages were due to a maximum peak ground acceleration of $205.97 \mathrm{~cm} / \mathrm{s}^{2}$, that is for the measured site period of 0.55 seconds, it was highly probable that at least a spectral pseudoacceleration at the site of $0.918 \mathrm{~g}$ was presented taking as a reference the response spectrum of the SAPP seismic station located at a hypocentral distance of $107 \mathrm{~km}$, similar to the hypocentral distance to the Ex convent of Atlatlahucan that was $85 \mathrm{~km}$. At the end, for the fundamental period of 0.343 seconds the elastic spectral ordinate was $0.52 \mathrm{~g}$, verifying a maximum acceleration of $0.65 \mathrm{~g}\left(640 \mathrm{~cm} / \mathrm{s}^{2}\right)$, which means that the vault suffered an elastic lateral seismic force equal to the $65 \%$ of its total weight.

\section{References}

[1] Programa de Diseño Sísmico, PRODISIS v4.1. IIE, Instituto de Investigaciones Eléctricas y Comisión Federal de Electricidad, México, 2015.

[2] Nakamura Y. A Method for Dynamics Characteristic Estimation of Surface Using Microtremors on the Ground Surface. Quarterly Report of Railway Tech Res, 1989.

[3] Meli R., García N. On structural bases for building mexican convent churches from the sixteenth century. International Journal of Architectural Heritage: Conservation, Analysis and Restoration, Vol. 3, Issue 2008, 1, p. 24-51.

[4] Hernández F., Barba J. M., Dávalos D., Martínez G., Rojas R. Propiedades dinámicas experimentales para los edificios históricos de la ciudad de Morelia. XVIII Congreso Nacional de Ingeniería Sísmica, Aguascalientes, Aguascalientes, Mexico, 2011, (in Spanish). 